
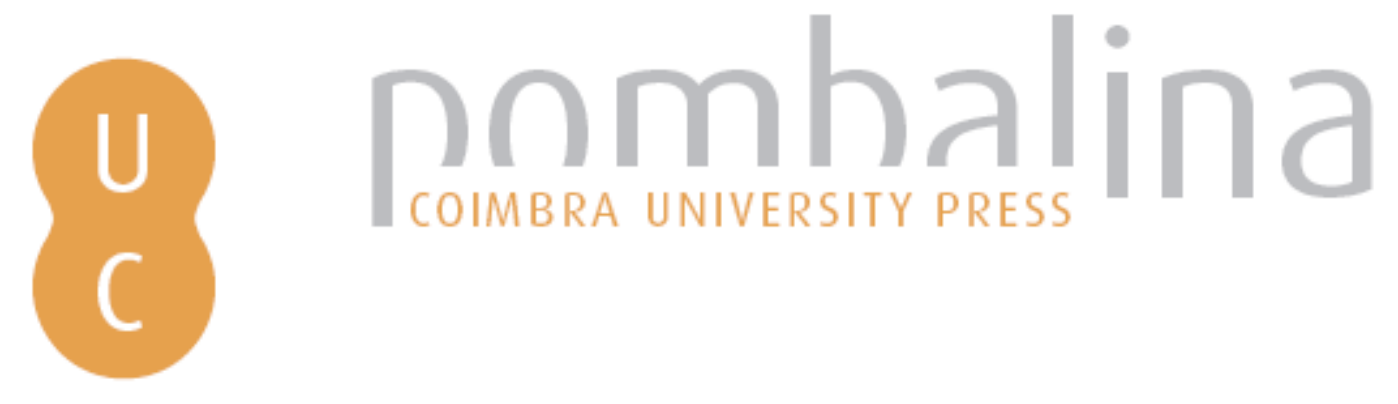

\title{
O contributo do Museu e Laboratório Mineralógico e Geológico da Universidade de Coimbra para os estudos de Paleontologia Africana
}

\author{
Autor(es): $\quad$ Callapez, Pedro; Gomes, Celeste; Pinto, Manuel Serrano; Lopes, \\ Fernando; Pereira, Luís Gama \\ Publicado por: Imprensa da Universidade de Coimbra; Laboratório de Radioactividade \\ Natural da Universidade de Coimbra \\ URL \\ persistente: \\ URI:http://hdl.handle.net/10316.2/36298 \\ DOI: \\ DOI:http://dx.doi.org/10.14195/978-989-26-1009-2_11 \\ Accessed : $\quad$ 26-Apr-2023 12:54:34
}

A navegação consulta e descarregamento dos títulos inseridos nas Bibliotecas Digitais UC Digitalis, UC Pombalina e UC Impactum, pressupõem a aceitação plena e sem reservas dos Termos e Condições de Uso destas Bibliotecas Digitais, disponíveis em https://digitalis.uc.pt/pt-pt/termos.

Conforme exposto nos referidos Termos e Condições de Uso, o descarregamento de títulos de acesso restrito requer uma licença válida de autorização devendo o utilizador aceder ao(s) documento(s) a partir de um endereço de IP da instituição detentora da supramencionada licença.

Ao utilizador é apenas permitido o descarregamento para uso pessoal, pelo que o emprego do(s) título(s) descarregado(s) para outro fim, designadamente comercial, carece de autorização do respetivo autor ou editor da obra.

Na medida em que todas as obras da UC Digitalis se encontram protegidas pelo Código do Direito de Autor e Direitos Conexos e demais legislação aplicável, toda a cópia, parcial ou total, deste documento, nos casos em que é legalmente admitida, deverá conter ou fazer-se acompanhar por este aviso.

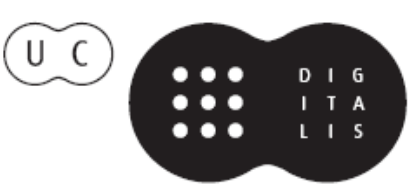




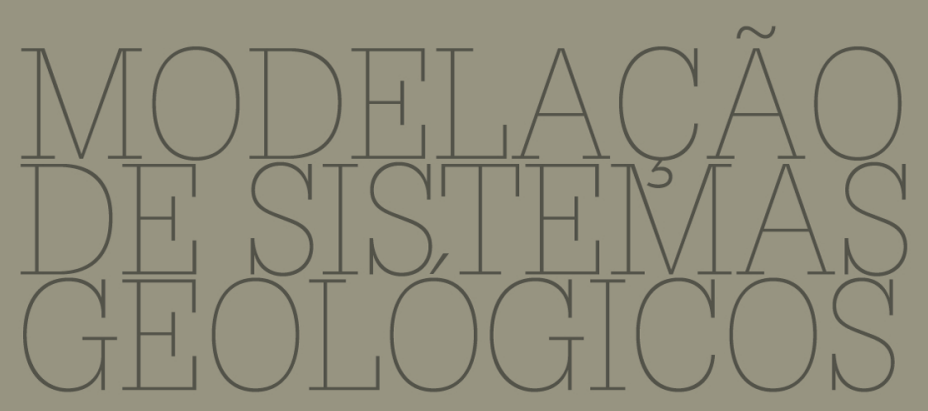

Homenagem ao Professor Doutor Manuel Maria Godinho

L.J.P.F. Neves, A.J.S.C. Pereira,

C.S.R. Gomes, L.C.G. Pereira,

A.O. TAVARES

IMPRENSA DA UNIVERSIDADE DE COIMBRA

CoImBra University Press 


\title{
O contributo do Museu e Laboratório Mineralógico e Geológico da Universidade de Coimbra para os estudos de Paleontologia Africana
}

\author{
Pedro Callapez'; Celeste Gomes ${ }^{2}$; Manuel Serrano Pinto ${ }^{3}$; Fernando Lopes²; \\ Luís Gama Pereira ${ }^{2}$ \\ ${ }^{1}$ Departamento de Ciências da Terra e Centro de Geofísica da Universidade de Coimbra, PORTUGAL. \\ E-mail: callapez@dct.uc.pt \\ ${ }^{2}$ Departamento de Ciências da Terra e Centro de Geofísica da Universidade de Coimbra, PORTUGAL. \\ ${ }^{3}$ Departamento de Geociências - GeobioTec da Universidade de Aveiro, PORTUGAL.
}

Palavras-chave: Universidade de Coimbra, Geologia Africana, Historial de pesquisas, Análise documental

\section{Resumo}

O Museu e Laboratório Mineralógico e Geológico da Universidade de Coimbra, herdeiro da Secção de Mineralogia e Geologia do Museu de História Natural (1885) e, mais tarde, repartido pelas estruturas do Departamento de Ciências de Terra e do Museu Mineralógico e Geológico, desempenhou um papel algo tardio, mas mesmo assim brilhante, no estudo, ensino e divulgação da Paleontologia dos antigos territórios coloniais africanos, prestigiando a Universidade e divulgando uma revista científica própria (Memórias e Notícias, desde 1921). Embora existisse a intenção de nutrir o museu com amostras e espécimes africanos, pelo menos desde a década de 40 do século XIX, os acervos de minerais, rochas e fósseis só começaram a ser constituídos mais de 50 anos depois. Os estudos geológicos tiveram início com o Prof. Anselmo Ferraz de Carvalho e, mais tarde, sob a égide do Prof. Cotelo Neiva (1950 em diante). Na Paleontologia de Angola, Moçambique e/ou São Tomé e Príncipe destacaram-se Gumerzindo Henriques da Silva (entre 1953 e 1972), António Ferreira Soares (entre 1959 e 1970) e Armando Moura (entre 1958 e 1976), entre outros. Na sua maioria, os grupos taxonómicos abordados por estes autores foram os moluscos bivalves, gastrópodes e cefalópodes e os equinídeos do Cretácico e Miocénico, apresentando os estudos preocupações de ordem sistemática e estratigráfica. A grande qualidade destes estudos é corroborada pelos estágios internacionais que efectuaram e pelo volume significativo de correspondência mantido com especialistas das principais instituições científicas europeias da época, ligadas à Paleontologia. No presente estudo é feita uma análise destes contributos e dos acervos deles resultantes, a par de uma recensão da bibliografia que traduz o contributo efectivo de Coimbra na época áurea para os estudos africanos, que foram as décadas de 50 a 70 do século passado. 
Key-words: University of Coimbra; African Geology; History of researches; Documentary analysis

\begin{abstract}
The Mineralogical and Geological Museum and Laboratory of the University of Coimbra were a main unit of the Faculty of Sciences during the XX century. It originated from the earlier Section of Mineralogy and Geology of the Natural History Museum (1885) and was subdivided, after 1992, in both the Earth Sciences Department and the Mineralogical and Geological Museum. Side by side with many other contemporaneous activities of this structure, the research, teaching and outreach of Paleontology from the ex-Portuguese African territories was marked by a rather late, but still significant contribute that gathered reputation to the University, also with the creation of a scientific journal (Memórias $e$ Noticias, since 1921).Although the intention to supply the Museum with African samples and specimens was noticeable at least since the 1840's, the collections of minerals, rocks and fossils began only to be assembled more than 50 years later. The geologic studies were initiated with Prof. Anselmo Ferraz de Carvalho. Some years afterwards they continued under the direction of Prof. Cotelo Neiva (1950 onwards). Concerning the works of Paleontology of Angola, Mozambique and/or São Tomé and Príncipe, the emphasis goes to Gumerzindo Henriques da Silva (from 1953 to 1972), António Ferreira Soares (from 1959 to 1970) and Armando Moura (from 1958 to 1976), among others. With a few exceptions, the taxonomic groups studied by these workers were Cretaceous and Miocene bivalves, gastropods, cephalopods and echinoids. Most studies deal with systematic, taxonomic and biostratigraphyic problems, and their pertinence and quality have been confirmed by a significant volume of scientific contacts with foreign institutions and specialists of Paleontology. In the present study we make a brief analysis of these works and related collections, as well as a review of the literature of the real contribution of Coimbra during the golden era of African studies that were the 1950's to 1970's of last century.
\end{abstract}

\title{
Uma perspectiva histórica
}

Os caminhos dos portugueses pelas sete partidas do Mundo conduziram, desde os alvores do Renascimento, a um redescobrir do misterioso continente africano, afeiçoando os seus contornos em portulanos inovadores, até ao estabelecimento definitivo da carreira da Índia. Com tamanha ambição para um povo tão pouco numeroso, cedo se viu África preterida pelas pérolas do Oriente e do Brasil, ficando-se por Moçambique (a ilha), pela Mina e por um pequeno número de outros entrepostos de reabastecimento e de socorro, enquanto a História Trágico-Marítima de Sepúlveda ia enriquecendo, pouco a pouco, os seus anais sinistros.

Criadas as lucrativas roças do Brasil e de São Tomé e declinando a luz que os Gama e os Albuquerque tão bem ergueram no firmamento, o interesse por África ressurgiu na figura do hediondo comércio de escravos, 
assim se podendo, em grande parte, explicar o crescimento das zonas de influência portuguesa ao longo dos litorais de Angola e de Moçambique.

Desta forma se passaram três séculos, enfrentando a cobiça da Companhia das Indias holandesa e a acção nefasta dos corsários. Mesmo abolida a vergonha na metrópole e entrando em retrocesso o esclavagismo, as possessões africanas da Coroa portuguesa continuaram a ser locais pouco recomendados, para onde seguiam aventureiros e degredados, balanceados entre uma perspectiva de enriquecimento fácil e a morte pelas febres ou às mãos dos indígenas.

Desta forma se explica o facto de, perante a política expansionista da Velha Albion e do neoimperialismo de França e de Bismarck, Portugal se encontrasse numa posição de considerável debilidade que a razão histórica pouco ou nada mitigou. A conferência de Berlim (1884-85) e o malogrado projecto do Mapa Cor-de-Rosa apenas contribuíram para relegar para segundo plano o ultramar português na divisão colonial do continente Africano, enfraquecendo a monarquia e abrindo caminho para o advento da República.

Não obstante o forte impacte negativo que tiveram na afirmação internacional do país, estes incidentes também acabaram por instigar as instâncias governativas nacionais para a necessidade de um acréscimo substancial do esforço de investimento em Angola e Moçambique. Iniciado, sobretudo, após o desbravar do interior pelos pombeiros e com as grandes viagens científicas de exploração de Serpa Pinto, Hermenegildo Capelo e Roberto Ivens $(1869,1877-79$, 1884-85), entre outras de menor imediatismo, este esforço teve por fim: (1) a afirmação e o exercício efectivo da soberania no interior dos territórios sob administração portuguesa; (2) a expansão territorial; (3) o conhecimento geográfico e a demarcação de fronteiras; (4) o conhecimento científico nas vertentes zoológica, botânica, antropológica, etnográfica e geológica; (4) a descoberta e exploração de recursos naturais e de matérias-primas estratégicas; (5) a selecção de áreas favoráveis para produção agrícola e a fixação de colonos.

Compreende-se, deste modo, o importante papel que os inúmeros estudos e missões geológicas vieram a desempenhar nas décadas seguintes, começando pelo simples envio de amostras para as instituições metropolitanas vocacionadas para as Ciências da Terra, mas evoluindo para uma fase de apogeu, já nas décadas de 1950 e 1960, durante as quais se efectuavam extensos levantamentos cartográficos e se identificavam e exploravam jazidas de interesse mineiro. No entanto, nada foi fácil e, mesmo durante os anos duros do Estado Novo, em que o regime exacerbava o esforço da raça e o Império Colonial Português, os protagonistas dos 
estudos de Geologia africana lutaram com dificuldades de vária ordem. Assim o demonstra Carríngton da Costa (1943), ao traçar uma panorâmica dessa envolvência, quando o desenrolar da guerra ainda acarretava incertezas quanto à manutenção das colónias.

Os estudos de Paleontologia africana estiveram, por sua vez, quase sempre ligados aos de Estratigrafia, numa preocupação sentida de definir as grandes unidades sedimentares aflorantes nestes territórios e de proceder ao seu ordenamento relativo. Assim se entende o interessante opúsculo ilustrado de Paul Choffat (1912), editado pela Secção de Geologia da Sociedade de Geografia de Lisboa, numa perspectiva de desenvolvimento colonial: Indicações sobre o modo de colligir amostras geologicas.

Dentro dos domínios da geologia histórica é por demais evidente que a primazia dos estudos coloniais coube à $3^{\mathrm{a}}$ Comissão Geológica do Reino, mais tarde Serviços Geológicos de Portugal (Brandão, 2008). Não resistimos a lembrar, também, o interessante opúsculo de José de Anchieta (1885), denominado Traços Geológicos da Africa Occidental Portugueza, pelo seu pioneirismo e por ser o primeiro de que temos conhecimento, a ser editado in loco (Figura 1).

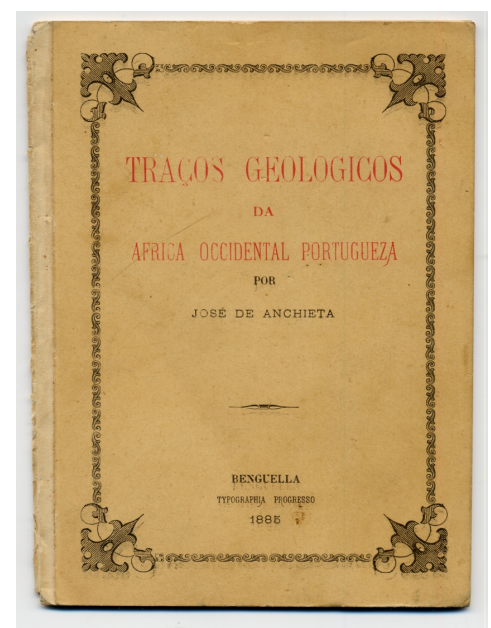

Figura 1. Frontispício do opúsculo pioneiro de José de Anchieta (1885), impresso em Benguella (col. Pedro Callapez).

De qualquer forma e até finais da Primeira República, os meios ligados aos estudos coloniais centraram-se, sobretudo, nos círculos académicos da capital, restando a Coimbra e ao Porto papéis de certo modo expectantes. Nas páginas seguintes procuraremos relevar a emergência da 
Universidade de Coimbra, em particular nos estudos de Paleontologia (e Estratigrafia), mais pungentes durante o Estado Novo.

\section{Primórdios da Geologia ultramarina no Museu de Coimbra}

As colecções geológicas da Universidade de Coimbra representam um registo precioso de mais de dois séculos de ensino e investigação científica em Ciências da Terra, fruto do contributo de várias gerações docentes e investigadores das faculdades de Filosofia e de Ciências. A sua origem deve-se, em primeira instância, à reforma pombalina da universidade (1772) e à criação do gabinete de História Natural, no que constitui uma das primeiras instituições portuguesas vocacionadas para o ensino e experimentação em Mineralogia, Geognosia, Metalurgia e Arte de Minas, através de laboratórios apetrechados com modelos e colecções de amostras.

Ao cunho indelével de Domingos Vandelli (1730-1816) seguiram-se, durante mais de meio século, os contributos significativos de alguns dos lentes que lhe sucederam, com destaque para José Bonifácio, Manuel José Barjona, Paulino de Nola e Roque Fernandes Thomaz (Portugal Ferreira, 1990, 1998). Graças à sua dedicação, as colecções primitivas com origem no Museu Real da Ajuda e em acervos particulares, foram acrescentadas, sobretudo, com conjuntos numerosos de minerais e rochas de proveniências europeias diversas, mas também do Brasil, ao tempo a jóia da coroa e uma fonte permanente de novos produtos naturais.

Neste contexto, o Gabinete e, mais tarde, o Museu de História Natural de Coimbra, deve ser julgado como uma estrutura de carácter universitário, destinada a promover o conhecimento e a experiência prática de grupos restritos de alunos, em detrimento de uma abertura ao público, em geral. Assim, foi ao longo da sua longa existência, funcionando também como repositório de colecções científicas, ligadas ou não a dissertações, em que a preocupação estética era secundária perante a singularidade ou o manancial de dados inerente a cada espécime ou amostra.

Sob a designação de petrificados os fósseis sempre representaram um grupo de somenos importância nestes acervos anteriores ao último quartel do século XIX, não obstante a existência de alguns conjuntos de interesse museológico e/ou importância estratigráfica, enquanto demonstrativos das idades dos terrenos. Desta forma, quer devido à pouca vocação dos estudos académicos nesse sentido, quer por força de alguma inércia ou escassez de fundos, pouco ou nada terá sido tentado para enriquecer as colecções geológicas com espécimes portugueses ou africanos, pelo menos até à década de 40 do século XIX. Neste sentido, mais precisamente entre Janeiro 
e Março de 1845, a congregação de lentes da Faculdade de Filosofia endereçou ao governo de Costa Cabral um pedido formal acompanhado de extensa missiva a D. Maria II, no sentido de que o Ministro do Reino se dignasse ordenar às autoridades das possessões ultramarinas o envio de animais vivos e preparados, «a par de todo o tipo de outros produtos naturaes, quer orgânicos, quer inorgânicos».

Este interesse algo súbito pela História Natural colonial ocorreu num curto intervalo de alguma estabilidade política e de um certo impasse das instituições congéneres da capital, em que as antigas colecções da Ajuda e do Museu Maynense se procuravam encaixar nos vastos espólios da Academia das Ciências de Lisboa (Antunes, 1986, 2000) e a Escola Politécnica de Lisboa titubeava após o violento incêndio de Abril de 1843. As razões que o motivaram transcendem-nos de momento, sobretudo porque ainda escasseavam nas colecções geológicas espécimes da metrópole, muitos deles a um pequeno passo dos locais de recolha. Não obstante a sua aparente pertinência e estilo tão cuidado, o pedido às instâncias régias parece não ter dado frutos, visto que o cabralismo se desmoronaria meses depois, vergado pela revolta da Maria da Fonte, a que se seguiu o período de forte instabilidade da guerra da Patuleia.

Fica-nos, no entanto, uma primeira prova documental sobre o interesse pela geologia colonial, o qual só se viria a efectivar após a reforma de 1885, com a reestruturação do Museu de História Natural e a permanência do lente António José Gonsalves Guimarães à frente dos destinos da então Secção de Mineralogia e Geologia. Durante as duas décadas seguintes, os espaços museológicos e os laboratórios e salas de aula a eles apensos foram dotados de vastíssimas colecções internacionais de rochas, fósseis, minerais e modelos, compradas a diversos comptoirs europeus, com maior incidência na famosa casa Krantz. Em paralelo, tornaram-se mais frequentes as recolhas em território continental, chegando também as primeiras amostras de proveniência colonial, das quais destacamos os grandes frascos com fosfatos de Benguela, antes expostos na Exposição Insular e Colonial Portuguesa de 1894, ou ainda parte das amostras recolhidas por Rego Lima no Namibe e na Huíla, em 1898, como espólio da expedição às Minas de Cassinga (Os materiais e notas desta expedição ao planalto angolano foram, mais tarde, revistos por Francisco Pereira de Sousa, em 1911) (Figura 2).

Não obstante este esforço, verificou-se alguma marginalização da Universidade de Coimbra em relação às suas congéneres olisiponenses, não sabemos se casual, se forçada pelo dinamismo apreciável da Comissão Geológica, entronizada que estava com os sucessivos ministérios, com a 
Academia das Ciências e com a recém-criada Sociedade de Geografia. Brandão (2008, 2009, 2010a, 2010b) dá-nos uma excelente panorâmica desta actividade profícua e dos espólios daí resultantes, parte dos quais serviram para algumas das primeiras publicações de Paleontologia africana (Choffat, 1886, 1886-87; Choffat \& Loriol, 1888; Loriol, 1888; Choffat \& Gomes, 1898; Priem, 1907).

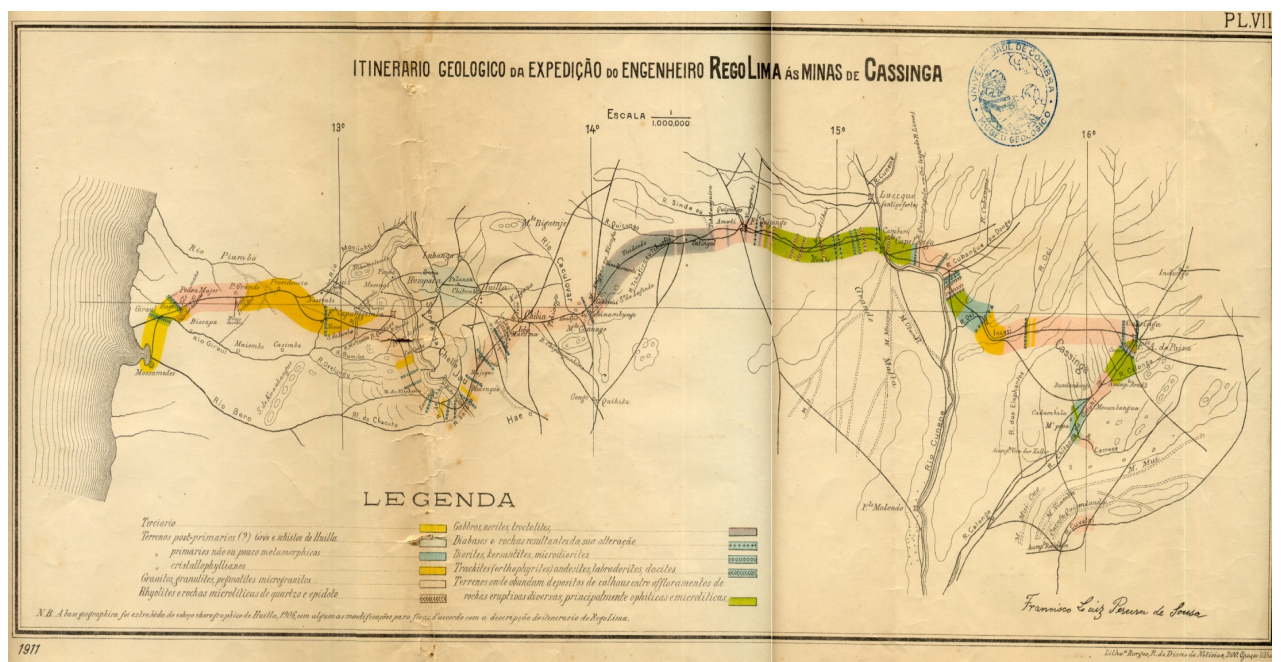

Figura 2. Itinerário da expedição de Rego Lima entre Namibe e as minas de Cassinga (1898) (segundo Sousa, 1911).

\section{Os estudos e colecções de Paleontologia africana}

Com o advento da República e a reforma de 1911 assistiu-se à criação da Faculdade de Ciências da Universidade de Coimbra, a par das Universidades de Lisboa e do Porto e do Instituto Superior Técnico. Nesta nova ordem e já findado o sacrifício português na Grande Guerra, consumado em prol da conservação dos antigos territórios africanos, surgiu o Museu e Laboratório Mineralógico e Geológico enquanto unidade anexa da Faculdade de Ciências, sob direcção de Anselmo Ferraz de Carvalho (Portugal Ferreira, 1998).

Herdeira dos acervos de Mineralogia e Geologia do século XIX, a nova estrutura cedo foi sendo renovada e engrandecida com colecções portuguesas, incluindo importantes conjuntos de fósseis cedidos pelos Serviços Geológicos de Portugal (1925). Em simultâneo com a projecção de novos estudos no arquipélago da Madeira, iniciados por José Custódio de Morais, o acervo colonial foi consideravelmente aumentado graças a novas 
ofertas, incluindo colecções de amostras de Júlio Henriques e da expedição de Baeta Neves à Lunda (1918-26) e numerosos fósseis recolhidos pela Missão Geológica de Angola, os quais terão sido cedidos, em 1927, por António de Sousa Torres, antigo aluno de Coimbra.

Foi, de igual modo, em 1921, que se iniciou a publicação do periódico Memórias e Notícias, no qual surgiu o primeiro de muitos estudos dedicados a temas coloniais, versando a Geologia e Paleontologia de Angola, São Tomé e Príncipe e Moçambique (Carvalho, 1921).

Após a instauração do Estado Novo, a política da tutela enveredou no sentido de exacerbar os valores da pátria, da raça e da família, projectando o país como sendo uma nação enraizada nos cinco continentes, através das suas possessões e do imenso peso histórico. Sob a égide do denominado Império Colonial Português, sobretudo a partir da Exposição Colonial do Porto (1934), foram fomentadas as explorações e os estudos ultramarinos, com certa ênfase nos de Geologia e Paleontologia, por serem susceptíveis de conduzir à descoberta e aproveitamento de novas riquezas minerais. Este espírito está bem presente em Vicente (1932), através de palestra publicada nas Memórias e Notícias (Callapez et al., 2008).

Verificou-se, desta forma, a adaptação do meio universitário a um estado de índole colonial, em que o interesse pelos territórios africanos passava, necessariamente, por quatro pontos: (1) afirmação de soberania e expansão territorial; (2) fixação de colonos e fundação de colonatos; (3) aproveitamento da mão-de-obra local; (4) exploração dos recursos agrícolas e naturais para benefício da metrópole. No Museu e Laboratório Mineralógico de Coimbra foi o tempo da criação da Galeria Ultramarina, vasta ala onde se foram expondo as colecções de amostras africanas e que teve o seu apogeu nas décadas de 50 e 60 do século XX, até que ventos de mudança se fizeram sentir (Figuras 3 e 4 ).

Consumada a sua nomeação como catedrático de Geologia, em 1949, deve-se sobretudo ao dinamismo de João Manuel Cotelo Neiva o excelente período de expansão porque passaram as Ciências da Terra em Coimbra. Os estudos de Paleontologia africana devem ser interpretados neste contexto, enquanto parte de um movimento mais amplo que abrangeu diversas outras áreas da Geologia e muitos outros professores, investigadores e alunos, entre os quais Manuel Maria Godinho (1963). Neste sentido, a Universidade de Coimbra acompanhou plenamente a necessidade sentida e o rumo adoptado pela Junta de Investigações do Ultramar e por outras instituições portuguesas ligadas à pesquisa científica, no intuito de incrementarem exponencialmente os estudos sobre ciências geológicas e biológicas em território africano. 
$\mathrm{Na}$ vertente da Paleontologia foi publicado, em 1953, um primeiro estudo da autoria de Gumerzindo Henriques da Silva, sobre a fauna fóssil de Inhaminga, em Sofala, Moçambique. Finalizada a licenciatura em Ciências Geológicas pela Universidade de Coimbra e após interregno de dois anos nas Minas do Pejão, Henriques da Silva ingressou no lugar de Naturalista do Museu e Laboratório Mineralógico, em Maio de 1955. Desde essa data e mesmo após a sua ida, cerca de 1965, como Técnico de Energia Nuclear e Electrónica (!) para os Estudos Gerais Universitários de Moçambique, foi autor de variados trabalhos sobre Paleontologia de São Tomé e Príncipe, Angola e Moçambique, a que acrescem diversas contribuições sobre a fauna quaternária de Porto Santo (Henriques da Silva, 1956, 1958a, 1958b, 1960, 1961a, 1961b, 1961c, 1962a, 1962b, 1962c, 1962d, 1963a, 1963b, 1963c, 1965, 1966a, 1966b, 1967, 1972; Henriques da Silva \& Ferreira Soares, 1962; Henriques da Silva et al., 1967).

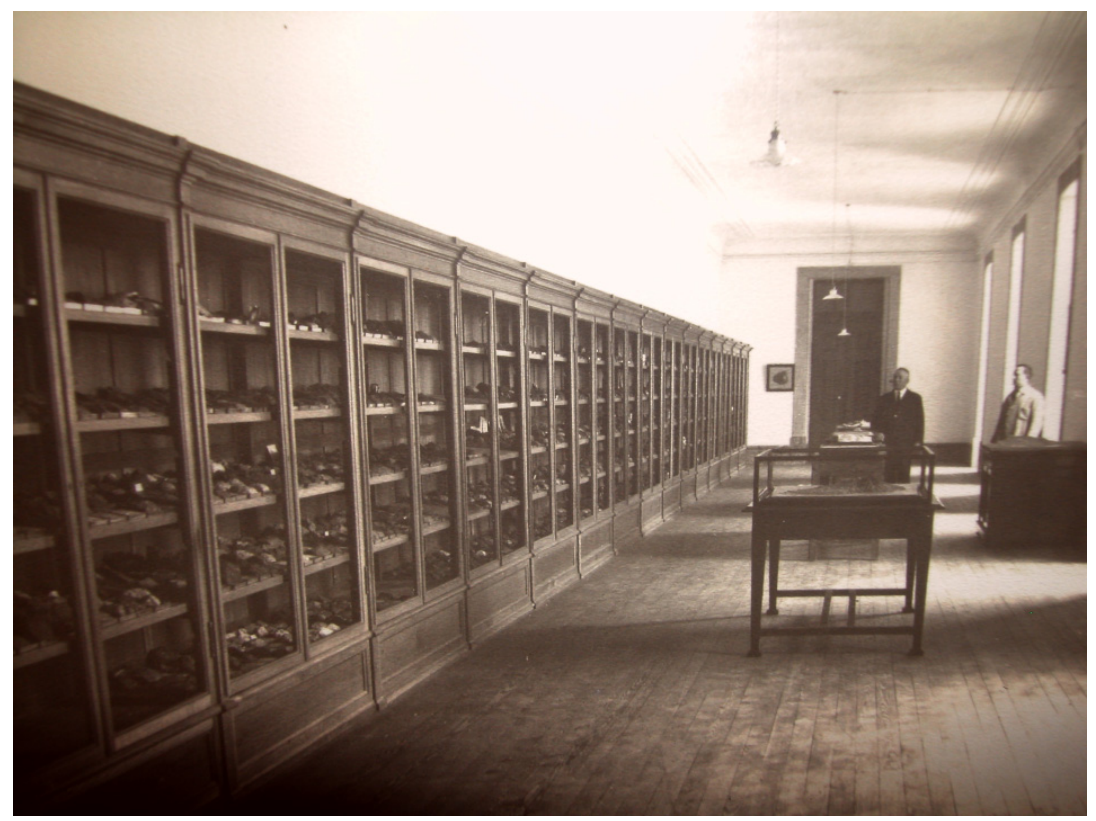

Figura 3. Panorâmica da Galeria Ultramarina do Museu de Coimbra nos anos $30 / 40$ do século XX. Notem-se as vitrinas das janelas ainda por colocar e os modelos em relevo de São Tomé (fonte: acervo documental do Departamento de Ciências da Terra da Universidade de Coimbra).

Em 1955 e 1957 surgiram, também, os trabalhos de Miguel Montenegro de Andrade - ao tempo Assistente do Museu e Laboratório - 
versando o Miocénico do Farol das Lagostas e uma panorâmica dos estudos de Paleontologia de Angola.

Foi precisamente no mesmo período que Gaspar Soares de Carvalho, também ele Assistente e Doutorado pela Universidade de Coimbra, com dissertação sobre a Estratigrafia e Sedimentologia da base do Mesozóico português (1946), se deslocou para Angola, com o intuito de chefiar uma brigada dos Serviços de Geologia e Minas encarregada de proceder ao levantamento geológico da orla sedimentar do Namibe (fins de 1955 a inícios de 1958). Deste estudo de campo exaustivo resultaram numerosos trabalhos, dos quais uma parte consiste em relatórios inéditos e outros ainda, encerram uma componente significativa de Paleontologia estratigráfica (Carvalho, 1960, 1961, 1967a, 1967b). Destes, a monografia de 1961 sobre a Geologia do Deserto de Moçamedes, elaborada no âmbito de uma dissertação para a obtenção do grau de Prof. Agregado da Universidade do Porto, constitui ainda hoje um dos grandes contributos para o conhecimento da geologia sedimentar dos países africanos de língua portuguesa.

Ao correr de um núcleo de Paleontologia ultramarina que, pouco a pouco, se ia constituindo em Coimbra, o ainda aluno de licenciatura António Ferreira Soares iniciou os seus estudos nesta área através da análise de colecções de fósseis da sua região natal (Ferreira Soares, 1958, 1959). Estes materiais de idade albiano-turoniana haviam sido cedidos por Mascarenhas Neto, dos Serviços de Geologia e Minas de Angola, com excepção de alguns espécimes de Tympanotus e de Arca, provenientes de jazida quaternária encontrada na quinta de família (Rocha et al., 2008). A partir de 1960, já Assistente, encarregou-se do estudo de novas colecções do Miocénico e do Cretácico de Angola (Ferreira Soares, 1961a, 1961b, 1962, 1963a, 1963b, 1965), entretanto cedidas pelos mesmos serviços, até que os trabalhos de tese o redireccionaram temporariamente para as formações cretácicas do Baixo Mondego. Mais tarde, já doutorado, permaneceu durante dois anos na Universidade de Lourenço Marques, onde voltou a colaborar com Gumerzindo em novos estudos sobre o Cretácico de Maputo (Ferreira Soares \& Henriques da Silva, 1969, 1970). 


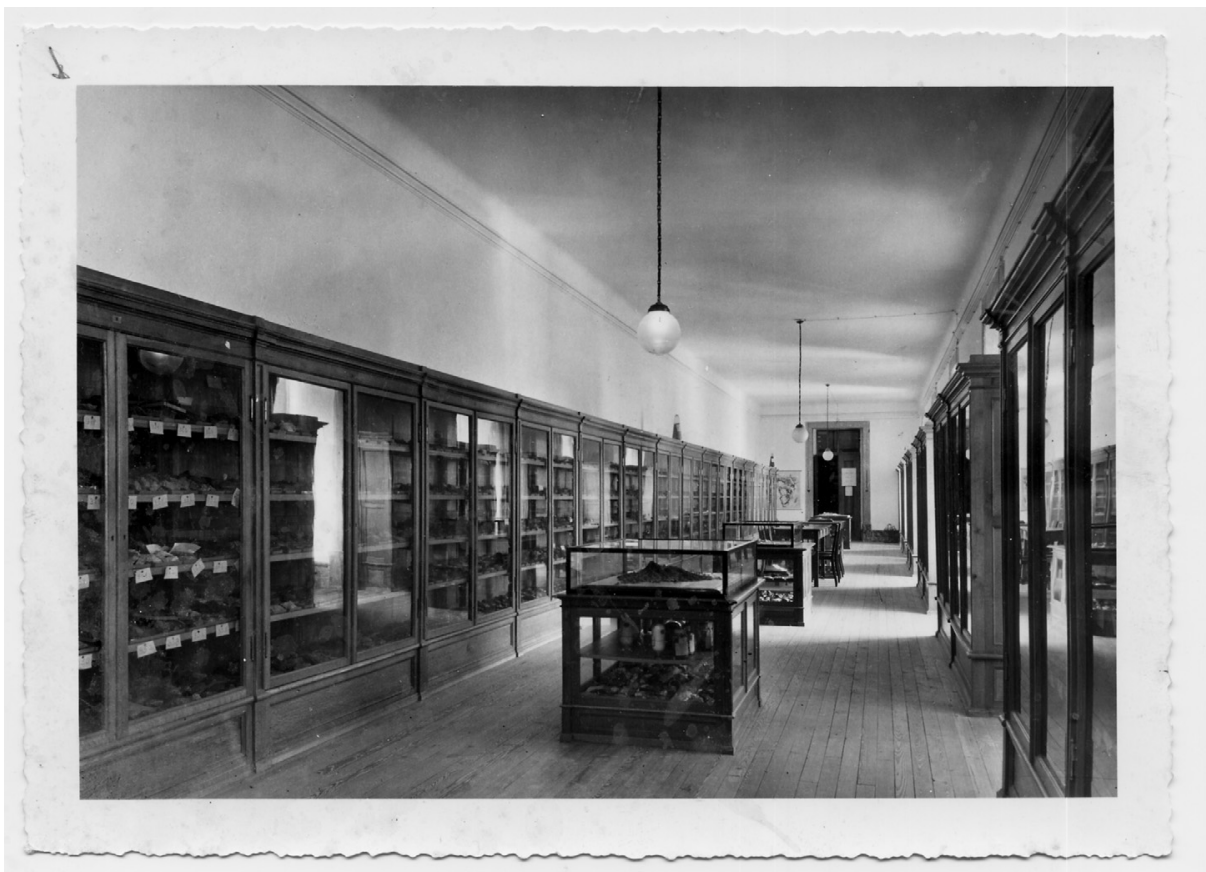

Figura 4. Panorâmica da Galeria Ultramarina do Museu de Coimbra nos anos 50 do século XX. Notem-se as vitrinas das janelas já colocadas, mais modelos em relevo e, na parede de fundo, a carta de África com as possessões portuguesas (fonte: acervo documental do Departamento de Ciências da Terra da Universidade de Coimbra).

Nos estudos de Paleontologia ultramarina com o cunho de Coimbra também é fundamental mencionar Armando Moura, aluno do Museu e Laboratório onde deixou, entre outros, um primeiro estudo sobre equinídeos portugueses (Moura, 1958). Embora não tenha ingressado nos quadros da instituição e tenha desenvolvido a sua actividade científica em Moçambique, sempre manteve contactos com os colegas do Museu. Deixou diversos trabalhos sobre Malacologia e Paleontologia (Moura, 1961, 1963, 1964, 1966, 1970, 1972, 1976), antes do seu regresso à metrópole e ligação à Universidade de Aveiro.

\section{Conclusões}

Como testemunho indelével e herança histórica de mais de meio século, durante o qual o Museu e Laboratório Mineralógico e Geológico de Coimbra participou activamente no desbravar do conhecimento geológico de Angola, Moçambique e São Tomé e Príncipe, ficou-nos um acervo considerável de colecções de amostras, das quais uma parte significativa 
consiste em fósseis de idade cretácica, miocénica e quaternária, enviados por elementos dos serviços geológicos coloniais para a metrópole. Embora conservado no espólio do extinto Museu de História Natural e aguardando a consumação do Museu da Ciência, este acervo ainda se encontra em parte por estudar e, ainda mais, por divulgar e expor, no sentido em que uma fracção importante da nossa história não se absorva nas espirais irreversíveis do passado.

A par de todas estas colecções fica a memória dos intervenientes, quase todos ainda entre nós e capazes de enriquecerem o registo histórico com as suas vivências e relatos inéditos. Como precioso elemento de pesquisa, fundamental para o retomar dos estudos geológicos nestes países e para o acalentar da cooperação que hoje já se verifica, existe também um significativo registo bibliográfico de obras de Paleontologia com a chancela de Coimbra, totalizando cerca de meia centena de títulos.

Estamos certos que a breve disponibilização destas obras em formato digital, assim como a recuperação dos espécimes e dos materiais-tipo das espécies de Angola e de Moçambique, novas para a Ciência, constituirão o melhor dos reconhecimentos da geração presente ao esforço de busca pelo conhecimento destes antigos colaboradores da Universidade de Coimbra.

Dedicatória: Os autores dedicam este trabalho ao Professor Doutor Manuel Maria Godinho pela sua enorme dedicação à investigação e ao ensino das Geociências.

Notas e agradecimentos: Trabalho publicado no âmbito do projecto FCT HC/0119/2009 (História da Ciência na Universidade de Coimbra (1547-1933).

\section{Bibliografia}

Anchieta, J. (1885) - Traços geológicos da África Occidental Portugueza. Typographia Progresso, Benguella, 12p.

Antunes, M.T. (1986) - Sobre a história da Paleontologia em Portugal. In: História e desenvolvimento da Ciência em Portugal, vol. II. Academia das Ciências de Lisboa, Lisboa, 773-814.

Antunes, M.T. (2000) - Paleontologia e Portugal. Colóquio/Ciências. Publ. Fundação Calouste Gulbenkian; 25, 54-75.

Brandão, J.M. (2008) - "Missão Geológica de Angola": contextos e emergência. Memórias e Notícias; n.s.; 3, 285-292.

Brandão, J.M. (2009) - O "Museu colonial" das Comissões Geológicas. Emergência e memória científica. Actas do XXIX encontro da Associação Portuguesa de História Económica e Social 
- Memória social, patrimónios e identidades. Fac. Letras da Univ. Porto, 13-14 Novembro, 2009.

Brandão, J.M. (2010a) - O acervo colonial das "Comissões Geológicas" de Portugal (1857-1918). Nota preliminar. In: J.M. Brandão; P.M. Callapez; O. Mateus \& P. Castro (Eds.) Geocollections: mission and management. Centro de História e Filosofia da Ciência da Universidade de Évora \& Museu Mineralógico e Geológico da Universidade de Coimbra, Coimbra - Capítulo 12, 113-120.

Brandão, J.M. (2010b) - O "Museu de Geologia Colonial" das Comissões Geológicas de Portugal: contexto e memória. Revista Brasileira de História da Ciência; 3 (2), Jul.-Dez. Rio de Janeiro.

Callapez, P.M., Marques, J.F., Matias, C. (2008) - Os estudos de Paleontologia ultramarina na Universidade de Coimbra e os fósseis do litoral de Benguela (Angola). Memórias e Notícias; n.s.; 3, 301-308.

Carríngton da Costa, J., (1943) - Problemas Geológicos Coloniais. Boletim da Sociedade Geológica de Portugal; 2, 1-26.

Carvalho, A.F. (1921) - Estudo Microscópico de rochas da Ilha de São Tomé. Memórias e Notícias; 1, 9-25.

Carvalho, G.S. (1960) - Estudo sobre os depósitos cretácicos do litoral de Angola. Boletim dos Serviços de Geologia e Minas de Angola; 1, 37-46.

Carvalho, G.S. (1961) - Geologia do deserto de Moçâmedes (Angola): uma contribuição para o conhecimento dos problemas da orla sedimentar de Moçâmedes. Memórias da Junta de Investigações do Ultramar; sér. II, 26, 227 p.

Carvalho, G.S. (1967a) - Uma síntese dos conhecimentos sobre o Cretácico da orla sedimentar de Moçâmedes (Angola). Garcia de Orta; 15, 225-248.

Carvalho, G.S. (1967b) - A cronoestratigrafia do Cretácico da orla sedimentar de Moçâmedes (Angola) e a análise de uma crítica. Lemos Ed., Porto, 44 p.

Choffat, P.L. (1886) - Sobre os terrenos sedimentares das províncias de África e considerações sobre a geologia deste continente. Jornal do commercio, $n^{\circ} 9926$ de 31 de Dezembro, Lisboa.

Choffat, P.L. (1912) - Elementos para a resolução dos problemas coloniaes. Parecer da Secção de Geologia. A) Explorações parcellares $-\mathrm{n}^{\circ} 2$. Indicações sobre o modo de colligir amostras geológicas. Ed. Sociedade de Geographia de Lisboa. Typographia da Cooperativa Militar, Lisboa, $12 \mathrm{p}$.

Choffat, P.L. (1886-1887) - Note préliminaire sur des fossiles recueillis par m. Lourenço Malheiro dans la province d'Angola. Bol. Soc. Geol. France; 3ème ser. 15, 154-157.

Choffat, P.L. \& Gomes, J.P. (1898) - Échantillons de roches recueillis entre Benguella et Catoco. Com. Dir. Trab. Geol. Port.; 3, 239-243.

Choffat, P.L., Loriol, P. de (1888) - Matériaux pour l'étude stratigraphique et paléontologique de la province d'Angola. Mem. Soc. Phys. Hist. Nat. Genève; 30, 97-1145.

Ferreira, Cor. V. (1932) - A política colonial portuguesa em Angola. Memórias e Notícias; 7, 5-73.

Ferreira Soares, A. (1958) - Sobre alguns fósseis da região de entre Lobito e Catumbela (Angola). Memórias e Notícias; 46, 11-22.

Ferreira Soares, A. (1959) - Contribuição para o estudo da fauna fóssil da região de entre Lobito e Catumbela (Angola). Garcia de Orta; 7, 1-20.

Ferreira Soares, A. (1961a) - Lamelibrânquios do Cretácico da região de Benguela-Cuio (Angola). Boletim do Serviço Geológico e Mineiro de Angola; 4, 1-62.

Ferreira Soares, A. (1961b) - Nouvelle espèce de Chlamys du Miocène de la région de Luanda (Angola). Memórias e Notícias; 51, 1-6.

Ferreira Soares, A. (1962) - Nota sobre alguns lamelibrânquios e gastrópodes do Miocénico de Luanda (Angola). Memórias e Notícias, 53, 31-35.

Ferreira Soares, A. (1963a) - Paleontologia de Angola - I. Sobre os lamellibrânquios cretácicos da região de Benguela-Cuio. Memórias e Notícias; 55, 1-25. 
Ferreira Soares, A. (1963b) - Paleontologia de Angola - III. Alguns lamellibrânquios cretácicos da região de entre o posto de S. Nicolau e a Mulola da Caniço a Sul do Chapéu Armado. Memórias e Notícias; 56, 35-40.

Ferreira Soares, A. (1965) - Contribuição para o estudo dos lamellibrânquios cretácicos da região de Moçamedes. Boletim do Serviço Geológico e Mineiro de Angola; 11, 1-34.

Ferreira Soares, A., Henriques da Silva, G. (1969) - Sobre a ocorrência do Senoniano na margem esquerda do Rio Maputo (região de Madubula). Revista de Ciências Geológicas; série A; 2, 1 7.

Ferreira Soares, A., Henriques da Silva, G. (1970) - Contribuição para o estudo da geologia do Maputo: estratigrafia e paleontologia da região de Madubula e suas relações com áreas vizinhas. Revista de Ciências Geológicas; série A; 3, 1-85.

Godinho, M.M. (1963) - Tapiolite de Cavala, Alto-Ligonha, Moçambique: nota prévia. Memórias e Notícias; 56, 41-44.

Henriques da Silva, G. (1953) - Fauna fóssil de Inhaminga. Memórias e Notícias; 34, 1-12.

Henriques da Silva, G. (1956) - La faune Miocène de l'Ile du Prince. Memórias e Notícias; 42, 29-51.

Henriques da Silva, G. (1958a) - Nota sobre a microfauna do Miocénico marinho da Ilha do Príncipe. Memórias e Notícias; 45, 56-59.

Henriques da Silva, G. (1958b) - Contribuição para o conhecimento da microfauna do Miocénico marinho da Ilha do Príncipe. Garcia de Orta; 6, 507-510.

Henriques da Silva, G. (1960) - Contribuição para o conhecimento da paleontologia da região entre Moçâmedes e Porto Alexandre, Angola. Garcia de Orta; 8, 371-384.

Henriques da Silva, G. (1961a) - Alguns fósseis da região de entre Moçamedes e Porto Alexandre. Memórias e Notícias; 51, 9-17.

Henriques da Silva, G. (1961b) - Ammonite nouvelle du Campanien de la Barra do Dande. Memórias e Notícias; 51, 19-23.

Henriques da Silva, G. (1961c) - Sobre a fauna ictiológica do Farol das Lagostas (Luanda, Angola). Memórias e Notícias; 52, 75-84.

Henriques da Silva, G. (1962a) - Ammonites du Crétacé infèrieur du Maputo (Catuane, Mozambique). Memórias e Notícias; 53, 1-25.

Henriques da Silva, G. (1962b) - Amonites do Cretacico inferior do Rio Maputo (Catuane Moçambique). Boletim dos Serviços de Geologia e Minas de Moçambique; 29, 1-30.

Henriques da Silva, G. (1962c) - Fósseis do Miocénico de Luanda (Angola). Assoc. Port. para o Progresso das Ciências. Actas do XXVI Congresso Luso-Espanhol (Porto, 22-26 de Junho de 1962), secções II e IV, 3 p.

Henriques da Silva, G. (1962d) - Contribuição para o conhecimento do aptiano do distrito de Lourenço Marques (Moçambique). Assoc. Port. para o Progresso das Ciências. Actas do XXVI Congresso Luso-Espanhol (Porto, 22-26 de Junho de 1962), secções II e IV, 4 p.

Henriques da Silva, G. (1963a) - O género Anacorax no Cretácico superior de Angola. Memórias e Notícias; $55,25-41$.

Henriques da Silva, G. (1963b) - Paleontologia de Angola - II. Sobre os lamelibrânquios do Cretácico da região Carunjamba - Salinas - S. Nicolau. Memórias e Notícias; 56, 27-34.

Henriques da Silva, G. (1963c) - Lamelibrânquios do Cretácico da região Carunjamba - Salinas, S. Nicolau (Angola). Boletim do Serviço Geológico e Mineiro de Angola; 8, 1-67.

Henriques da Silva, G. (1965) - Contribuição para um catálogo dos lamelibrânquios fósseis do Cretácico de Moçambique. Revista dos Estudos Gerais Universitários de Moçambique, série VI - Ciências Geológicas; 2, 1-42.

Henriques da Silva, G. (1966a) - Sobre a ocorrência do Jurássico marinho no Norte de Moçambique. Revista dos Estudos Gerais Universitários de Moçambique, série II - Ciências Geológicas; 3, 61-68.

Henriques da Silva, G. (1966b) - Contribuição para um catálogo dos gastrópodes fósseis do Cretácico de Moçambique. Revista dos Estudos Gerais Universitários de Moçambique, série VI Ciências Geológicas; 3, 77-97. 
Henriques da Silva, G. (1967) - Fósseis do Miocénico marinho das plantações Santiago (Magude). Revista dos Estudos Gerais Universitários de Moçambique, série VI - Ciências Geológicas; 4, $1-21$.

Henriques da Silva, G. (1972) - Notas sobre paleontologia moçambicana. I - Pinna robinaldina d'Orbigny do Cretácico Inferior de Moçambique. Revista de Ciências Geológicas; série A, 5, 56-59.

Henriques da Silva, G., Ferreira Soares, A. (1962) - Contribuição para o conhecimento da fauna miocénica de S. Pedro da Barra e do Farol das Lagostas (Luanda, Angola). Garcia de Orta; 9, 721-736.

Henriques da Silva, G., Barreto, L.S., Carvalho, L.H.B. (1967) - Dadoxylon micoli seward do Karroo de Tete. Revista dos Estudos Gerais Universitários de Moçambique, série VI - Ciências Geológicas; 4, 37-59.

Loriol, P. de (1888) - Note sur la géologie de la province d'Angola. Arch. Sci. Phy. et Nat., Janvier, 3ème ser.; 19, 67.

Malheiro, L. (1881) - Explorações geológicas e mineiras nas colónias portuguezas. Conferência na Sociedade de Geografia de Lisboa, 26 p.

Montenegro de Andrade, M., Montenegro de Andrade, J. (1955) - A propósito de um corte geológico no Farol das Lagostas (Luanda, Angola). Memórias e Notícias; 39, 36-42.

Montenegro de Andrade, M., Montenegro de Andrade, J. (1957) - Estado actual dos conhecimentos sobre a paleontologia de Angola até fins de 1955. Anais da Junta de Investigações do Ultramar; $12,5-21$.

Moura, A.R. (1958) - Alguns equinídeos regulares fósseis da Costa d'Arnes. Memórias e Notícias; $45,61-72$.

Moura, A.R. (1961) - Contribuição para o conhecimento dos foraminíferos das praias levantadas de S. Tomé e Príncipe. Garcia de Orta; 9, 751-758.

Moura, A.R. (1963) - Cinco espécies novas de diatomáceas subfósseis para Moçambique. Boletim da Sociedade Broteriana; 37, 147-159.

Moura, A.R. (1964) - Contribuição para o conhecimento dos Diatomitos do Sul do Save (Moçambique). Bol. Serv. Geol. Min. Moçambique, 32, 7-45.

Moura, A.R. (1965) - Foraminíferos da Ilha da Inhaca. Revista dos Estudos Gerais Universitários de Moçambique; série II, 2, 1-74.

Moura, A.R. (1966) - Gastrópodes dos recifes corais elevados de Messonta e Matibane (Moçambique). Revista dos Estudos Gerais Universitários de Moçambique; série II, 3, 1-55.

Moura, A.R. (1968) - Moluscos dos grés costeiros da ilha da Inhaca. Revista de Ciências Biológicas; série A, 1, 16-52.

Moura, A.R. (1970) - Contribuição para o conhecimento da fauna subfóssil do Mucoque (Vilanculos). Revista de Ciências Biológicas; série A 3, 55-95.

Moura, A.R. (1972) - Contribuição para o conhecimento dos moluscos subfósseis do Relanzapo (Nacala, Moçambique). Revista de Ciências Biológicas; série A, 5, 9-66.

Moura, A.R. (1976) - Contribuição para o conhecimento da fauna malacológica subfóssil de Bartolomeu Dias (Inhassoro-Moçambique). Memórias do Instituto de Investigação Científica de Moçambique, série A - Ciências Geográficas e Geológicas; 42-87.

Portugal Ferreira, M.R. (1990) - O Museu de História Natural da Universidade de Coimbra (Secção de Mineralogia e Geologia) desde a Reforma Pombalina (1772) até à República (1910). Memórias e Notícias; 110, 53-76.

Portugal Ferreira, M.R. (1998) - 200 anos de Mineralogia e Arte de Minas: desde a Faculdade de Filosofia (1772) até à Faculdade de Ciências e Tecnologia (1972). FCTUC, Gráfica de Coimbra Ltda., Coimbra, 188 p.

Priem, F. (1907) - Poissons tertiaires des possessions africaines du Portugal. Com. Com. Serv. Geol. Port.; 7, $74-79$.

Rocha, R.B., Callapez, P.M., Marques, J.F. (2008) - A Paleontologia na obra de António Ferreira Soares. In: Callapez, P.M.; Rocha, R.B.; Cunha L.; Marques, J.F. \& Dinis, P.M. (Eds.) - A 
Terra Conflitos e Ordem. Livro de Homenagem ao Professor António Ferreira Soares, pp. 716. Ed. M.M.G.U.C., Coimbra, XXII + 478 p.

Sousa, F.P. (1911) - Alguns trechos do relatório do Engenheiro Rego Lima sobre a sua missão ás minas de Cassinga. Typographia do Commercio, Lisboa, $247 \mathrm{p}$. 